\title{
Urban energy consumptions: its determinants and future research
}

\author{
R. Papa, C. Gargiulo, F. Zucaro, G. Angiello \& G. Carpentieri \\ Department of Civil, Architectural, and Environmental Engineering, \\ University of Naples Federico II, Italy
}

\begin{abstract}
The population growth of those living in urban areas reaches $50 \%$ of the total population, causing air pollution and energy consumption, which is also due to the high density of urban activities. This gradual process of urbanization, which covers an area equal to $2 \%$ of the world, is responsible for about $75 \%$ of the total consumption of resources. Although cities are the place where there is a wide concentration of energy demand and consumption, the attention given to the implications of this phenomenon is still inadequate. These considerations allow to perceive that such things require a broader strategy to solve the problem, based on the integration of urban, transport and environment policies for sustainable development. According to this awareness, the National Operative Programme (PON) funded "Smart Energy Master for the management of territory" has been developed; it is aimed at supporting local authorities in the development of strategies and tools for the reduction of energy consumption through actions designed to change behaviour (in terms of use and energy consumption). This paper describes some of the first results of the project, to develop a comprehensive/interpretive model at the urban scale. The paper is divided into three parts: the first part describes the current consumptions and future trends of building and transport sectors, focusing the attention on urban areas; the second part offers an overview of the main studies related to physical/functional characteristics of the city, buildings and transport; and the third part offers some causes for reflection on the need to change the range of interventions, to reduce urban energy consumption.
\end{abstract}

Keywords: energy consumption, urban form, energy parameters, energy building models. 


\section{Background and goals}

The European Union is one of the largest energy consuming regions in the world. In 2012, EU-28 final energy consumption reached 1.104 Mtoe - approximately $15 \%$ of the world's energy consumption (EC [1]). A third of this amount was consumed by the transport sector $(31.7 \%)$, the most energy-demanding sector, followed by households $(26.6 \%)$, the industrial sector $(25.3 \%)$ and services (20.4\%). Over recent decades, there has been a decoupling of the energy consumption from the GDP although transport energy consumption has increased much more than in other sectors.

Forecasts to 2030 suggest that energy consumption in Europe will increase in all major sectors and that the transport sector will experience the fastest growth, increasing by $28 \%$ between 2000 and 2030 (EC [2]). Energy efficiency improved by $12 \%$ at EU level between 2000 and 2010 (1.2\%/year) but there has been a net slowdown in energy efficiency gains since the economic crisis: $0.6 \% /$ year since 2007 , compared to $1.5 \%$ /year before.

Since few years, due to the expiration of the Kyoto Protocol (2012), the European authorities have started a process of negotiation amongst the member states to define shared goals of intervention, in order to formulate a new and more sustainable Community strategy. In 2009, this decision making process led to the approval of Directive 2009/29/ which commits the member states to break down the total greenhouse gas emissions at least $20 \%$ by 2020 , compared to the emission values in 1990. In particular, within this timeframe, the member states, through the definition of the 20-20-20 Strategy, aim at the achievement of three main objectives: the reduction of the global energy consumption $(-20 \%)$, the reduction of emission gases that alter the climate $(-20 \%)$, and the increase of the consumption of energy produced from renewable sources $(+20 \%)$. In establishing these strategies, the European government bodies have emphasized the need to integrate energy security and support for growth with competitiveness and employment, using an approach that combines high technology, efficiency in terms of cost and efficiency in the use of resources (COM(2013)169 final). To continue acting in this direction, EU has recently also launched a review of the Climate-Energy Package, with the aim of providing a more certain framework to investors, identifying a longer timeframe, up to 2050 . As recently clarified by the European Commission in the Green Paper "A framework for energy and climate policies to 2030" (2013), this timeframe extension aims at both stimulating further innovation and demand for low-carbon technologies and allowing to the EU, according to the future global agreements for climate post-2020, to have a clear policy line to be followed during negotiations.

In the near future the energy consumption challenge will be played mainly in cities. Thanks to the advance of industrial development and the consequent spread of social welfare, since the nineteenth century there has been a gradual and continuous increase of world population living in urban areas. This phenomenon reached its peak in the last decade, when the number of people living and working in urban areas overcame that of rural. In consequence, a growing demand for new urbanized areas has risen, to meet the needs of these new citizens of urban areas. 
The negative effects due to this new form of urban development have been immediately clear and the subsequent decrease in quality of life has occurred together with the enormous consumption of natural resources. Therefore, making decision processes that aim at equilibrating land-use policies with environmental protection ones, has become more and more urgent during recent decades. These kind of processes are the focus of future development decisions made at European, national and local levels, in order to balance the demands of settlement with the reduction of pollutant emissions and limit the consumption of natural resources: "the step that EU is trying to accomplish is to propose new forms of urban development and governance in order to prevent the problems that until now have been solved a posteriori" (Gargiulo et al. [3]).

Analyzing the energy end use in the 27 European Countries at 2011 is possible to observe that there are large variations between countries. These variations are even more noticeable at urban scale, especially comparing European city's end-use consumption with American and Asian cities. Indeed, cities worldwide show extremely different energy end-use distribution according to their size, their stage of economic development and their land use and transport patterns. For instance, in the cities of the wealthier industrialized world, most energy is used for residential and commercial buildings, followed by the transport and the industrial sector. On the contrary, in megacities such as Beijing, Shanghai and Kolkata, industries consume more than $50 \%$ of total energy uses, reflecting the fast growth of Chinese and Indian economies, while in large cities of countries whose economies are growing at a slower pace, the transport sector consumes more than half of the total energy used (UN-HABITAT [4]).

In order to make the importance of the urban dimension within the energy issue understand, the purpose of this paper is to review the current literature on the relationships between the main urban components and energy consumptions. In particular, this paper seeks to identify the determinant of energy consumption in urban areas by reviewing evidences from empirical studies.

\section{Current literature}

The aim of this section is an overview of the most recent literature on the energy consumptions at urban scale, focusing on physical and functional characteristics of city, buildings and transports. These three study fields represent just some of the different sector involved in the project SEM, such as the socio-economic one, the non-residential buildings and the urban green areas, in order to develop the comprehension/interpretive model, based on the interrelations among the different urban components.

Even though the knowledge framework has been built up by the several researches and models that cut across all the different interested areas, in this paper we want to describe some of the results related to those elements of the urban system that can be considered as the most important from the energy perspective.

According to what has been explained in the previous section, in fact, buildings and transports are responsible for the most energy consumptions in cities and they are strictly related to the physical and functional organization of urban systems. 
The relation between the spatial configuration of settlements and energy issue becomes more obvious if considering the evolution and changes in urban land use (Dale et al. [5]; Forman [6]), resulting, for example, from the construction of plants for the production of electricity, but even more if reflecting on the reciprocal influences in terms of geometry and urban microclimate.

These last two elements are the ones on which the most recent scientific debate has been developed: on the one hand, scholars such as Owen [7], Salat [8] and Ewing and Rong [9] have analyzed how urban density, design and form can affect the energy consumptions and on the other, those who have questioned about the dependence of energy needs on solar gains, thermal comfort and so urban microclimate (Givoni [10]; Steemers [11]; Ratti and Morello [12]). In particular, researches related to the first brain researches are focused on understanding the relationship between urban density and energy efficiency, trying to find a balance point in dispute between the contradictory theories about urban form: the compact city and the dispersed city.

Compactness is more energy efficiency than the urban sprawl, thanks mainly to the limited vehicle travels (related to the mixed land-use) and the size of the housing units. Nevertheless compact form affects in a negative way both passive solar conditioning and opportunities for solar-energy generation, as a building's roof could be shaded by another's. Hence the attention of scholars on how the physical features of the urban built environment act on the availability of sunlight and the urban microclimate.

All the studies briefly described above claim the important role of parameters such as territorial density, building orientation, surface/volume ratio, open and green areas concerning the energy consumptions, but what seems still lacking is the awareness that a better and more efficient energy performance of cities can be reached through a their integration and correlation (Salat and Nowacki [13]). The study of morphology, physical urban structure or building energy consumption, if not deepened from a systemic analysis point of view that includes all the other components of the urban system, is still inadequate if compared to the complexity of the issue. This reflection is confirmed by the results of the researches conducted so far on the energy consumptions at urban scale, that can often be biased and inconsistent and which do not take account of systemic visions.

Although it is established that the urban form can produce or mitigate heat island effects, the effort that should be done, is to understand and assess if and how the form can affect the energy behavior and consumption patterns of users, as they make decisions related to and several possible activities that affect energy uses and emissions.

The study of the energy consumptions at urban scale concerned the bottom-up models too, due to the fact that most scientific interest has been pointed to the minute scale such as the building one. The choice of the models to be described and analysed, related to residential building energy consumptions, has been based on two main criteria: the most recent developed models and those applicable also to a territorial level of suburban scale.

The Residential Building Typology is a bottom-up model of engineering type that uses the method of archetypes. This study was carried out by the research 
group THEBES of Polytechnic University of Turin through the analysis of the Italian existing building stock, identified a matrix of building types, consisting of 32 buildings-types. The matrix divided the different types of building by two main variables: the time of construction and the average size. Specifically, for each building-type, the annual energy consumptions of primary energy for heating and domestic hot water have been identified, and the numerical value assigned was calculated taking into account the different physical characteristics of the building (construction type and type of plants). One of the problems emerging from the analysis of this study, is the lack of information regarding the energy demand of buildings for cooling.

The Method to Analyze Large Data Sets of Residential Electricity Consumption to Inform Data-Driven Energy Efficiency was developed as part of the research activities carried out at the Department of Civil and Environmental Engineering at Stanford University. The input data for this model have been collected by an online survey consisting of 114 questions. A limitation of this model is that households selected for the collection of data belong exclusively to upper-middle class and have a high standard of education. The study has identified 22 variables that are most representative of the households' behaviour with respect to energy consumption.

The Residential Electricity Consumption Model in Portugal analyses the energy consumption in the residential sector, paying particular attention to the influence of the housing and households characteristics. The results of this model show that policy decisions that take into account only the income of families don't affect much on the variation in energy consumption for residential buildings, because other aspects such as the demographic structure of the population and housing characteristics are more influential.

The Community Domestic Energy Model (CDEM) is a bottom-up engineering model that uses the method of archetypes; thanks to this method, the model estimates $\mathrm{CO} 2$ emission, basing on the study of the physical characteristics of the building, the leaks heat, the internal temperature and the energy flows of dwellings (Kavgic et al. [14]). In order to characterise the 47 different classes of buildings, 27 input parameters have been considered and divided into five primary categories: location, geometry of buildings, construction features, services and population.

The study of all these models the parameters that affect residential building energy consumptions are: climatic zone, green areas, building age, building size, surface and compactness factor.

In regard to transport sector, it is worth noting that travel patterns in the metropolitan areas of most developed countries are increasingly car-dependent, (Rode [15]). Car dependency has currently become a political priority for European Union due, among other factors, to the environmental problems caused by this mobility pattern. Concerns over the negative environmental and energy impacts of urban mobility have prompted a substantial body of literature on the relationship between urban form, travel patterns and transport energy consumption. The debate on the relationship between urban form and transport energy consumption was activated by the publication of Newman and 
Kenworthy's [16] research. Using a sample of 32 cities in different countries and continents, they tested the influence of population density levels on the consumption of gasoline. The authors found that low-density metropolitan areas are associated with an almost total predominance of automobile use and consequently a higher pre-capita transport energy consumption. In contrast, high-density metropolitan areas present lower pre-capita transport energy consumption and a more balanced modal distribution with a share in public transport, ranging from 40 to $60 \%$ of travel. The hypothesis of a negative correlation between urban density and energy consumption in the transportation system has been further supported by various studies. In order to provide a direct estimate of the elasticity of energy demand with respect to urban density, Karathodorou et al. [17] estimated a fuel demand model for urban areas. Using a sample of 84 cities from 42 different countries, they found that urban density affects fuel demand and that it has also a significant impact on car ownership and yearly distance travelled per car. Brownstone and Golob [18] use the California subsample of the 2001 National Household Travel Survey to investigate the connections among residential density, vehicle usage and energy consumption. Using structural equation models, they found that population density influences households' fuel consumption trough two main channels: density directly influences vehicle usage, and both density and usage influence fuel consumption. According to Banister [19] there are two main reasons why population density may reduce the environmental footprint of mobility. First, high-density patterns reduce the commute distance between work destinations and home; second, highdensity patterns may be more amenable to public transport supply. The latter two hypothesis have been further tested in numerous studies. For instance, Cervero and Murakami [20] found a significant inverse effect of population density on vehicle miles travelled, while found a significant inverse effect of population density on vehicle miles travelled, while Giuliano and Narayan [21] found that high level of densities are positively related with a greater share in public transport.

While population density has received considerable attention in the literature, the influence of other factors such as urban structure, road density, city size and accessibility on transport energy consumption has been less often investigated. Shim et al. [22] analyzed the relationships between urban form and energy consumption, using a sample of 61 Korean cities. They described the urban structure of the Korean cities using the Gini coefficient for population concentration and compared the population Gini coefficient with yearly gasoline consumption per automobile and per person. Shim and his colleagues found that the energy efficiency is generally low in mononuclear cities, whereas the energy efficiency is high in multinuclear cities.

$\mathrm{Su}$ [23] studied the effect of freeway road density, congestion and population density on household gasoline consumption in 50 U.S. urban areas. His analyses suggest that households living in areas characterized by higher freeway densities, higher levels of congestion, or lower population densities consume more gasoline. The hypothesis of a positive relationship between road density and travel demand in terms of vehicle miles traveled has been tested in others studies such as that by Fulton et al. [24] and Nolan and Cowart [25] among others. These studies support 
the concept of induced demand, in accordance with which the additions to roadway capacity result in increases in vehicle travel on the roadway above the level that occurred before the capacity addition.

Banister [26] analyzed the relationships between city size and transport energy efficiency of a sample of English cities. His analyses shown that energy efficiency increase as the population increase. However, when the city size is over it is optimal level, a further increase in city size result in a decrease of energy efficiency due to congestion. Others research such as that of Chen et al. [27] said that the efficiency would be better as the size of city grew but it would be worse in bigger cities than the optimal size.

The literature discussed above has reported on analysis of various different dimensions of the relationship between urban patterns and transport energy consumption. However, even after many years of scientific and policy debate, there is still little consensus about the impact of land use on transport energy consumption. Some authors conclude that land use may have a significant impact on energy consumption in transport (Newman and Kenworthy [16]; Karathodorou et al. [17]), while others have found no, or hardly any, impact (Mindali et al. [28]; Stead [29]). Some say influencing energy consumption via land-use planning is an illusion (Downs [30]), while others say it is a very fundamental way to achieve sustainable mobility patterns (Breheny [31]; Black [32]).

\section{Conclusions}

Since several years a growing number of international research groups are questioning about approaches, methods and tools aimed at energy savings in urban areas. However, there is not still a strengthened conceptual framework allowing to compare in a uniform and shared manner the results obtained, and to develop effective solutions for reducing energy consumption at urban scale, taking into account the strict interrelations among the urban components.

So far the energy challenge in cities has been mainly engaged from the building, technology, socio-economic and transport point of view in a separate way, paid less attention to the urban dimension of this topic, which is characterized by looking at the whole of all the elements structuring the urban systems. The researches at urban scales do not seem to take into consideration these complex effects and they just simulate and analyze the influences on energy consumptions from one aspect. However, on the one hand the complex and multidimensional nature of the energy issue, intrinsic characteristics of urban systems too, on the other hand the territorial significance of the energy systems, should make clear that it is not possible to separate the issues of saving and energy efficiency from those of development, transformation and urban environment. (Papa et al. [33]).

The city is the historical place of concentration of energy demand: during the evolution of social organization forms, energy consumptions have thickened, in different ways and different quantities, in those strategic places that are cities. If this statement seems obvious, the implications and consequences of this relationship are less obvious, because they are still dealt with a weak approach, compared to the initial significance of the assumption. 
The framework outlined in this paper makes us understand the need to adopt a holistic approach that allows to act on the relationships of systemic elements of the city, in order to have a significant impact on energy consumption. This new way of dealing with the issue needs to be reflected not only from a theoretical and scientific point of view, but, above all, it should be consolidated at the level of action. The results reached by acting almost exclusively at the building scale, both for existing and for new construction buildings, are quite modest, compared to the goals of sustainable energy and environmental policy, established at a community and international level.

In order to significantly improve the energy performance of urban systems, it is necessary that the government policies of territorial transformations abandon the "building-centric" intervention logic to adopt a broader scale of intervention, like that of the district, which includes not only the buildings, but the relationships among all the elements involved: distribution of activities, means of transportation, users' socio-economic and energy habits.

In this context the SEM project fits, which is aimed at the development of a comprehension/interpretive model of energy efficiency of the territory, by a holistic approach. The strength of this project is to adopt a "logic of area" which refers to the scale of the neighbourhood, to better understand the relationships and synergies established between the urban components mentioned above, in the perspective of energy saving. Considering together all the determinant elements of the urban system, means to allow identifying the discriminating factors of energy consumption referred to a portion of the city area respect to another, and therefore developing new solutions for the energy government of territorial transformations.

\section{References}

[1] EC, www.ec.europa.eu/statistics

[2] EC, European Energy and Transport - Trends to 2030; Office for Official Publications of the European Communities, Luxembourg, 2003.

[3] Gargiulo C., Pinto V. \& Zucaro F., EU Smart city governance. TeMA Journal of Land use, Mobility and Environment. 6(3), pp. 355-370, 2013.

[4] UN-Habitat. State of the world's cities 2008/2009: Harmonious cities, Earthscan, London, 2008.

[5] Dale V.H., Efroymson R.A. \& Kline K.L., Thelanduse - climate change energy nexus. LandscapeEcol. 26(6), pp. 755-773, 2011.

[6] Forman R.T., Land mosaics: the ecology of landscapes and regions, Cambridge University Press: Cambridge, UK, 1995.

[7] Owen, S., Energy, planning and urban form, Peon, London, 1986.

[8] Salat S., L'efficacité énergétique dans la forme urbaine, Construire pour un développement durable, AFEX, 2008.

[9] Ewing R., \& Rong F., The impact of urban form on US residential energy use. Housing Policy Debate. 19(1), pp. 1-30, 2008.

[10] Givoni B., (1989), Urban design in different climates, World Metereological Organisation. (346), 1989. 
[11] Steemers K., Energy and the city: density, buildings and transport. Energy and buildings. 35(1), pp. 3-14, 2003.

[12] Ratti, C., \& Morello E., Sun Scapes: extending the 'solar envelopes' concept through isosolar surfaces. Proceedings of the $22^{\text {nd }}$ International Conference on Passive and Low Energy Architecture, Beirut, 2005.

[13] Salat S., \& Nowacki C., De l'importance de la morphologie dans l'efficience énergétique des villes, Liaison Energie Francophonie. 86, 2010.

[14] Kavgic M., Mavrogianni A., Mumovic D., Summerfield A., Stevanovic, Z., \& Djurovic-Petrovic M., A review of bottom-up building stock models for energy consumption in the residential sector. Building and Environment. 45(7), pp. 1683-1697, 2010.

[15] Rode P., Trends and Challenges: Global Urbanisation and Urban Mobility. Institute for Mobility Research (ed.) Megacity Mobility Culture: How Cities Move on in a Diverse World, Springer: Berlin Heidelberg, pp. 3-21, 2013.

[16] Newman P.W.G., \& Kenworthy J.R., Cities and automobile dependence. An international sourcebook, Gower Technical: Aldershot, 1989.

[17] Karathodorou N., Graham D. J. \& Noland R. B., Estimating the effect of urban density on fuel demand. Energy Economics. 32(1), pp. 86-92, 2010.

[18] Brownstone D., \& Golob T. F., The impact of residential density on vehicle usage and energy consumption. Journal of Urban Economics. 65(1), pp. 91-98, 2009.

[19] Banister D., Sustainable development and transport. Report for the Bundesforschungsanstalt für Landeskunde un Raumordnung. The Urban 21 Project, 1998.

[20] Cervero R., \& Murakami J., Effects of built environments on vehicle miles traveled: evidence from 370 US urbanized areas. Environment and Planning A. 42(2), pp. 400-418, 2010.

[21] Giuliano G., \& Narayan D., Another look at travel patterns and urban form: the US and Great Britain. Urban studies. 40(11), pp. 2295-2312, 2003.

[22] Shim G. E., Rhee S. M., Ahn K. H., \& Chung S. B., The relationship between the characteristics of transportation energy consumption and urban form. The Annals of Regional Science. 40(2), pp. 351-367, 2006.

[23] Su Q., The effect of population density, road network density, and congestion on household gasoline consumption in US urban areas. Energy Economics. 33(3), pp. 445-452, 2011.

[24] Fulton L. M., Noland R. B., Meszler D. J., \& Thomas J. V., A statistical analysis of induced travel effects in the US mid-Atlantic region. Journal of Transportation and Statistics. 3(1), pp. 1-14, 2000.

[25] Noland R. B., \& Cowart W. A., Analysis of metropolitan highway capacity and the growth in vehicle miles of travel. Transportation. 27(4), pp. 363-390, 2000.

[26] Banister, D. (1992). Energy use. Transport and settlement pattern. In: Breheny M.J. (ed) Sustainable development and urban form. Pion, London, pp. 160-181.

[27] Chen Y., Li X., Zheng Y., Guan Y. \& Liu, X., Estimating the relationship between urban forms and energy consumption: a case study in the Pearl 
River Delta, 2005-2008. Landscape and urban planning. 102(1), pp. 33-42, 2011.

[28] Mindali O., Raveh A., \& Salomon I., Urban density and energy consumption: a new look at old statistics. Transportation Research Part A: Policy and Practice. 38(2), pp. 143-162, 2004.

[29] Stead D., Relationships between land use, socioeconomic factors, and travel patterns in Britain. Environment and planning B. 28(4), pp. 499-528, 2001.

[30] Downs, A., Still stuck in traffic: Coping with peak-hour traffic congestion, The Brookings Institution: Washington, DC, 2004.

[31] Breheny M., The compact city and transport energy consumption. Transactions of the Institute of British Geographers. 20, pp. 81-10, 1995.

[32] Black J., Higher density housing and transport in Australian cities. Transport, Land Use and the Environment, ed. Hayaashi Y., Roy J., Kluwer Academic Publishers: Netherlands, pp. 55-80, 1996.

[33] Papa R., Gargiulo C., \& Galderisi A., Towards an urban planners' perspective on smart city. TeMA Journal of Land use, Mobility and Environment. 1, pp. 5-17, 2013. 